\title{
RESPON SEMUT TERHADAP KERUSAKAN ANTROPOGENIK DALAM HUTAN LINDUNG SIRIMAU AMBON (Ants Response to Damage Anthropogenic in Sirimau Forest Ambon)
}

\author{
Fransina Latumahina $^{1 *}$, Musyafa $^{2}$, Sumardi $^{2}$ dan Nugroho Susetya Putra ${ }^{3}$ \\ ${ }^{1}$ Program Doktor Ilmu Kehutanan, Universitas Gajah Mada Yogyakarta, \\ Jl. Agro No.1 Bulaksumur, Sleman Yogyakarta 55281. \\ ${ }^{2}$ Fakultas Kehutanan, Universitas Gajah Mada Yogyakarta, \\ Jl. Agro No.1 Bulaksumur, Sleman Yogyakarta 55281. \\ ${ }^{3}$ Fakultas Pertanian, Universitas Gajah Mada Yogyakarta. \\ Jl. Flora Bulaksumur, Sleman Yogyakarta 55281. \\ *Penulis korespondensi. No Tel: 0911-362194. Email: fransina.latumahina@yahoo.com
}

Diterima: 29 Januari 2015

Disetujui: 7 April 2015

\begin{abstract}
Abstrak
Penelitian bertujuan untuk mengkaji respon semut terhadap kerusakan habitat akibat kehadiran manusia dalam hutan lindung Sirimau Ambon. Penelitian dilaksanakan dari bulan Juni 2011 hingga Juli 2012. Respon semut diketahui dengan pendekatan kekayaan, kelimpahan, keragaman, frekuensi dan tanggap fungsional terhadap kerusakan antropogenik dalam hutan lindung melalui metode line transect. Parameter tambahan yang diamati adalah faktor iklim mikro, sifat fisik dan kimia tanah. Hasil penelitian menemukan 23 spesis semut, 16601 individu, kelimpahan spesis tertinggi sebesar 0,158, frekuensi 32,44 \% dan indeks keragaman sebesar 2,92 yang tergolong sedang. Kelompok fungsional semut terbagi menjadi kelompok oppurtunist (1 spesis), generalized myrmicinae (1 spesis), specialis predator (4 spesis), tropical climate specialis (6 spesis), dominant dolichoderinae (4 spesis), subordinate camponitini (6 spesis) dan criptic species (4 spesis). Faktor antropogenik yang menyebabkan kerusakan habitat hutan lindung yakni pembukaan wilayah hutan, penebangan pohon, pembakaran hutan, perladangan berpindah dan pembangunan fisik akibatnya terjadi fragmentasi dan degradasi habitat yang diikuti dengan ketidakseimbangan lingkungan dan komponen ekosistem.
\end{abstract}

Kata kunci: antropogenik, kerusakan habitat, komunitas semut, respon semut

\begin{abstract}
This study aims to know response ants to damage due to presence of human in Sirimau forest Ambon. The research was conducted from June 2011 until July 2012. Research to obtains data about richness, abundance, diversity, frequency and functional response from ants to anthropogenic damage in Sirimau forest with line transect method. Additional parameters measured were microclimate factors, physical and chemical of soil. The study found 23 species of ants, 16.601 individuals with highest species abundance of 0.158, 32.44\% frequency and diversity index of 2.92 were classified as moderate. Functionally ants found in the group classified are oppurtunist (1 species), generalized myrmicinae (1 species), specialist predators (4 species), tropical climate specialists (6 species), dominant dolichoderinae (4 species), subordinate camponitini (6 species) and criptic species (4 species). Anthropogenic factor have contribute to destruction of forest habitat through opening forests, logging, forest fires and shifting cultivation. Anthropogenic damage in secondary forest causing fragmentation and degradation, followed by imbalance of environment and ecosystem components.
\end{abstract}

Keywords: anthropogenic, ant communities, ant response, habitat destruction

\section{PENDAHULUAN}

Hasil interperetasi citra landsat 7ETM+ tahun 2009 menunjukkan adanya perubahan tutupan vegetasi dalam hutan lindung Sirimau Ambon Maluku. Perubahan ini terjadi akibat kerusakan antropogenik berupa pembukaan kawasan hutan untuk dijadikan areal pertanian, pemukiman, jalan raya, fasilitas pemerintah, penebangan pohon dan penggembalaan ternak oleh warga di sekitar hutan lindung. Akibat lebih lanjut adalah terbentuk klaster hutan sekunder seluas 578,58 ha (Anonim, 2009). Perubahan penggunaan lahan dan tutupan vegetasi berpotensi menimbulkan kerusakan habitat yang bermuara pada kemunculan degradasi dan transformasi habitat yang akan mengubah perilaku semut, diversitas semut, komposisi semut dan perubahan fungsi ekosistem dalam skala yang luas

Gejala transformasi habitat yang terjadi dalam hutan lindung Sirimau mengarah pada kerusakan parmanen dan bersifat kontinyu, sehingga dibutuhkan upaya untuk menyelamatkan potensi 
keragaman hayati guna mengembalikan fungsi dan peran sebagai hutan lindung di Kota Ambon. Upaya awal yang dilakukan adalah memantau kerusakan yang terjadi dalam kawasan hutan lindung Sirimau secara fisik, biologi dan kimia. Semut dipilih sebagai obyek dalam penelitian ini karena mempunyai arti ekologi yang penting dalam ekosistem hutan. Semut mampu menyediakan layanan ekosistem sebagai penyebar benih, pengendali hama secara biologis, predator, bioindikator lingkungan, seed harvester dan polinator (Garden dkk., 2007).

Holldobler dan Wilson (1990) menyatakan bahwa kehadiran semut dapat mengindikasikan kesehatan ekosistem dan memberikan gambaran tentang kehadiran organisme lain, karena banyaknya interaksi semut dengan berbagai tumbuhan maupun hewan lain. Semut dapat menjadi indikator biologi untuk menilai perubahan lingkungan karena mudah dikoleksi, biomassa dominan, taksonomi maju, dan sensitif pada perubahan lingkungan (Agosti dan Alonso, 2000) dan mampu merespon perubahan yang terjadi dalam ekosistem (Pecarevic dkk., 2010). Semut mempunyai korelasi yang kuat dengan variabel ekosistem yakni vegetasi, iklim mikro, tanah, dan fauna tanah lainnya (Shahabudin, 2011). Secara teknis pengambilan sampel semut relatif mudah dilakukan dan secara taksonomi mudah diidentifikasi sehingga semut dapat digunakan untuk membantu memahami kaidah ekologi, biomonitoring untuk tujuan konservasi dan pengelolaan hutan (Majer dan Nichols, 1998).

Beberapa studi tentang penggunaan semut sebagai indikator ekosistem telah banyak dipelajari di areal reklamasi tambang di Australia. Hasilnya menemukan bahwa pada areal bekas tambang tidak

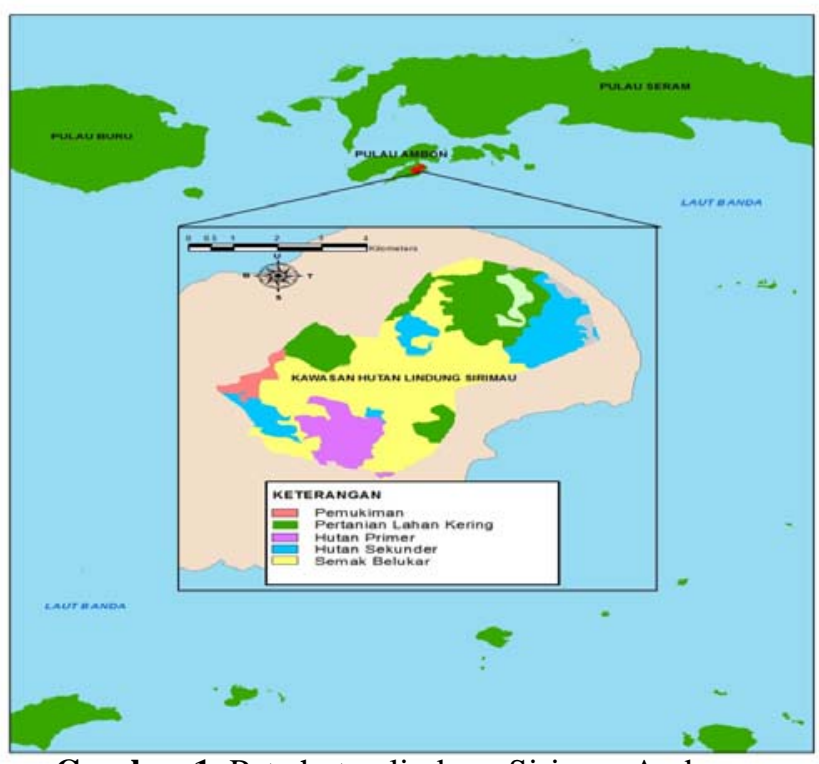

Gambar 1. Peta hutan lindung Sirimau Ambon. ditemukan semut yang mampu hidup dalam kurun waktu lima tahun (Majer dan Nichols, 1998). Faktor lingkungan sangat mempengaruhi kehadiran semut pada perkebunan kakao di Brasil karena faktor kandungan nitrogen pada tanaman yang ditanam dan sistem pengelolaan tanah yang dkerjakan dimana semut mengalami perubahan kehadiran, vitalitas dan memberikan respon terhadap praktek pengelolaan tanah (Pecarevic dkk., 2010). Berdasarkan uraian tersebut maka penelitian ini bertujuan untuk mengetahui respon semut terhadap kerusakan habitat serta hubungannya dengan faktor lingkungan.

\section{METODE PENELITIAN}

\section{Waktu dan Lokasi.}

Penelitian dilaksanakan dalam hutan sekunder seluas 578,58 ha yang merupakan bagian dari Hutan Lindung Sirimau Ambon (Gambar 1). Penelitian lapangan dilaksanakan bulan Juni 2011 hingga Juli 2012 dan dilanjutkan dengan pengamatan di Laboratorium Entomologi Dasar Fakultas Pertanian UGM pada bulan Agustus 2012 hingga Oktober 2012.

\section{Prosedur Penelitian.}

Penelitian dilaksanakan pada enam jalur pengamatan berukuran $500 \times 20 \mathrm{~m}^{2}$. Pengambilan semut menggunakan tiga metode, yakni pitfall trap (PT) atau perangkap jebak, bait trap (BT) dengan umpan gula dan ikan tuna serta hand collecting. Pitfall trap berupa gelas plastik berdiameter $\pm 7 \mathrm{~cm}$ dengan tinggi $\pm 10 \mathrm{~cm}$ yang diisi dengan $25 \mathrm{~mL}$ larutan air sabun. Pitfall trap ditanam sedalam \pm 10 $\mathrm{cm}$ dan diletakan pada tiap jarak $20 \mathrm{~m}$ dan ditinggalkan hingga sore hari kemudian diambil, disortir dan diidentifikasi. Bait trap dengan umpan larutan gula dan ikan tuna diletakan dalam piring plastik sebanyak 10 buah, digantung pada pohon tiap jarak $20 \mathrm{~m}$ dan ditinggalkan hingga sore hari baru dikumpulkan (Hashimoto dkk., 2001). Metode hand collecting dimana peneliti berjalan menyusuri jalur pengamatan selama satu jam dan mencari semut dan sarangnya yang hidup di sekitar tumbuhan yang rendah, di antara bebatuan, permukaan tanah, gundukan tanah dan patahan kayu (Andersen dkk., 2004). Sampel dikoleksi dengan pengawetan alkohol $70 \%$ dan diidentifikasi dengan mikroskop stereo binokuler hingga tingkat spesis.

\section{Analisis Data}

\section{Kerusakan habitat akibat kehadiran manusia.}

Tingkat kerusakan habitat didekati dengan pendekatan vegetasi. Analisis vegetasi meliputi kekayaan spesis, keragaman spesis, kelimpahan dan 
frekuensi vegetasi dapat menjadi indikator untuk menilai kerusakan habitat hutan sekunder akibat kehadiran manusia.

\section{Respon semut terhadap kerusakan hutan lindung.}

Respon semut terhadap kerusakan yang terjadi dalam hutan sekunder dianalisis menggunakan pendekatan nilai keragaman, frekuensi dan kelimpahan spesis semut. Pendekatan kelompok fungsional semut dalam hutan sekunder diklasifikasikan berdasarkan sistem pembagian kelompok fungsional semut di Australia dalam merespon tekanan dan gangguan yang terjadi dalam habitat (Andersen dkk., 2004). Parameter lingkungan diukur meliputi faktor iklim (Suhu dan kelembaban udara) serta faktor tanah ( $\mathrm{pH}$ tanah, suhu tanah dan kandungan bahan organik).

\section{HASIL DAN PEMBAHASAN}

\section{Kehadiran Manusia dan Kerusakan Habitat dalam Hutan Lindung}

Dalam surat keputusan Menteri Kehutanan nomor 871/Menhut-II/2013 tanggal 6 Desember 2013 menyebutkan bahwa luas hutan lindung di Propinsi Maluku tersisa 631,368,52 ha dengan laju deforestasi sebesar 283,2 ha/tahun (Anonim, 2013). Angka ini menunjukan bahwa kondisi hutan lindung di Maluku termasuk Hutan lindung Sirimau semakin memprihatinkan tiap tahun karena mengarah pada gejala degradasi dan transformasi habitat. Degradasi dan transformasi hutan disebabkan oleh faktor manusia (antropogenik) dan faktor alam (non antropogenik) di antaranya penebangan liar, pembakaran hutan, pembangunan pemukiman, sarana pemerintah, erosi, banjir dan serangan hama penyakit. Persentase kerusakan antropogenik dalam Hutan Lindung Sirimau akibat penebangan pohon (70,09\%), pembakaran hutan (54,23 \%), pengembalaan ternak ( $24,99 \%)$, pembangunan prasarana pemerintah (63,59\%), kegiatan bercocok tanam (45,88\%), pengambilan hasil hutan kayu (40,68 \%), pengambilan hasil hutan non kayu (15,96 \%), pembangunan perumahan (50,09 \%) dan kegiatan lainnya $(15,67$ \%) (Talaohu, 2012). Data ini memperlihatkan bahwa hutan lindung Sirimau telah mengalami kerusakan ekosistem yang berat akibatnya kehidupan komponen ekosistem mengalami gangguan termasuk semut yang hidup didalamnya.
Pengamatan visual peneliti menemukan bahwa kegiatan illegal logging atau penebangan liar dilakukan oleh warga sekitar hutan sekunder untuk dijadikan kayu bakar dan bahan bangunan yang dijual untuk meningkatkan pendapatan keluarga, pembakaran hutan secara sengaja oleh warga sekitar hutan lindung dilakukan dengan cara membakar untuk dijadikan pemukiman, kebun dan ladang. Warga membuka hutan untuk dijadikan ladang selama beberapa bulan, setelah tanah tidak lagi berproduksi warga berpindah mencari areal hutan baru. Perladangan berpindah dalam hutan Sirimau adalah warisan nenek moyang karena sudah menjadi tradisi dalam bercocok tanam bagi warga setempat pada saat musim kemarau. Pasca konflik di Kota Ambon, banyak warga kehilangan tempat tinggal, sehingga hutan lindung Sirimau dijadikan alternatif pengungsian bagi warga. Pembangunan sarana dan prasarana milik pemerintah pasca konflik diantaranya Instalasi Pengelolaan Sampah Terpadu (ITSP), jalan raya dan sarana kesehatan masyarakat dan penggembalaan ternak dimana warga menggembalakan ternak sapi dan kambing secara intensif dalam kawasan hutan .

\section{Kekayaan, Keragaman dan Kemerataan Jenis Vegetasi}

Kerusakan habitat dapat diketahui dengan menggunakan pendekatan faktor vegetasi yakni kekayaan jenis, keragaman dan kemerataan jenis vegetasi. Kekayaan jenis adalah jumlah individu dalam suatu komunitas yang dinyatakan dalam nilai indeks (Barbour dkk., 1999). Keragaman jenis adalah parameter yang berguna untuk membandingkan dua komunitas, terutama untuk mengetahui pengaruhnya dari gangguan biotik, atau untuk mengetahui tingkat suksesi serta kestabilan suatu spesis. Keragaman spesis ditandai dengan banyak spesis yang membentuk sebuah komunitas (Indriyanto, 2006). Kemerataan menunjukkan derajat kemerataan kelimpahan individu antar spesis, yang digunakan sebagai indikator gejala dominansi antara tiap spesis dalam suatu komunitas atau untuk mengetahui kemerataan satu spesis vegetasi dalam satu komunitas. Nilai ketiga parameter dapat dilihat pada Tabel 1.

Variasi nilai ketiga parameter diduga dipengaruhi oleh faktor iklim yakni suhu, kelembaban, $\mathrm{pH}$ tanah, curah hujan, sifat fisika dan kimia tanah. Hal ini sesuai dengan pendapat

Tabel 1. Kekayaan, keragaman dan kemerataan vegetasi dalam hutan lindung.

\begin{tabular}{lccccc}
\hline Parameter & Hutan primer & Hutan sekunder & Pertanian lahan kering & Semak - belukar & Pemukiman \\
\hline Kekayaan jenis & 9,87 ( Tinggi) & 7,75 ( Tinggi ) & 4,94 ( Sedang ) & 3,01 ( Rendah) & 3,65 (Rendah ) \\
Keragaman jenis & 3,67 ( Tinggi ) & 3,30 ( Sedang ) & 2,68 ( Sedang ) & 1,17 ( Rendah) & 1,36 ( Rendah) \\
Kemerataan jenis & 0,21 (Rendah) & 0,10 ( Rendah ) & 0,60 ( Sedang) & 1,22 ( Tinggi ) & 0,80 ( Tinggi) \\
\hline
\end{tabular}


Irwanto (2005) bahwa faktor iklim dan tanah sangat mempengaruhi pertumbuhan dan reproduksi vegetasi dalam kawasan hutan. Faktor klimatis juga mempengaruhi kekayaan vegetasi pada satu ekosistem karena berhubungan dengan radiasi matahari, temperatur udara, kelembaban udara, presipitasi dan angin (Soekotjo, 1976). Tinggi rendah suhu udara akan menentukan tumbuh kembang, reproduksi dan kelangsungan hidup tanaman. Suhu yang cocok untuk pertumbuhan vegetasi antara $22-37^{\circ} \mathrm{C}$ (Purwowidodo, 1996). Suhu yang lebih atau kurang dari batas normal mengakibatkan pertumbuhan yang lambat atau berhenti karena kadar air dalam udara dapat mempengaruhi pertumbuhan tanaman. Kelembaban yang tinggi menyebabkan pertumbuhan tanaman lebih cepat dan sebaliknya kelembaban rendah diperlukan untuk pertumbuhan generatif (Djayadiningrat, 1990).

Faktor ketinggian tempat memberikan pengaruh terhadap kekayaan vegetasi pada kelima klaster. Hutan primer terletak pada ketinggian 250 $525 \mathrm{~m}$ dpl, hutan sekunder 100 - $375 \mathrm{~m}$ dpl, pertanian lahan kering 50 - $250 \mathrm{~m}$ dpl, semakbelukar 75 - $525 \mathrm{~m}$ dpl dan pemukiman 100 - 200 $\mathrm{m}$ dpl. Perbedaan ketinggian tempat berpengaruh terhadap jumlah dan jenis vegetasi namun bersifat tidak langsung, artinya perbedaan ketinggian tempat akan mempengaruhi keadaan lingkungan tempat tumbuh pohon terhadap suhu, kelembaban, oksigen di udara, dan keadaan tanah. Meskipun pengaruhnya tidak langsung, tetapi berpengaruh terhadap keragaman vegetasi (Djayadiningrat, 1990). Tekstur atau susunan pertikel tanah, air tanah, temperatur tanah, dan unsur hara yang terkandung di dalam tanah juga berpengaruh terhadap perbedaan vegetasi yang tumbuh di atasnya (Soekotjo, 1976). Serangan hama dan penyakit kategori sedang hingga sangat berat pada tusam (Pinus merkussi Jung Et De Vriese) dengan ulat api coklat (Milonia basalis), ekaliptus (Eucaliptus alba) dengan Hellopeltis spp, akasia (Acacia mangium) dengan kupu-kupu kuning (Eurema spp), jati (Tectona grandis) dengan Hiblaea puera juga mempengaruhi komposisi dan keragaman spesis vegetasi (Sahusilawane, 2010).

Kehadiran manusia berkaitan dengan kekayaan vegetasi pada kelima klaster. Dalam hutan primer ditemukan aktivitas perburuan oleh warga namun tidak secara kontinyu, pada hutan sekunder ditemukan aktivitas pengambilan kayu, galian C dan hasil hutan non kayu untuk dijadikan bahan bangunan meskipun intensitasnya juga tidak terlalu tinggi. Pada klaster pertanian lahan kering, aktivitas warga cukup tinggi. Warga menebang pepohonan untuk bercocok tanam, mengambil dedaunan untuk makanan ternak, membuat kebun, mengembalakan ternak serta pengambilan pasir dan batu. Pemerintah juga ikut andil dengan program pembangunan pemukiman bagi warga pengungsi pasca konflik, pembangunan jalan raya, serta ITSP. Dalam klaster semak - belukar ditemukan kegiatan penggembalaan ternak secara kontinyu, pengambilan batu dan pasir, dan kebakaran akibat kekeringan juga ikut mempengaruhi kekayaan vegetasi dalam klaster ini. Pada klaster pemukiman ditemukan perumahan warga yang dibangun secara parmenen maupun semi parmanen, adanya pekuburan umum serta aktivitas manusia lainnya.

Index diversitas vegetasi pada kelima klaster berkisar dari sedang hingga tinggi. (Tabel 1). Hutan primer dan sekunder memiliki keragaman vegetasi tinggi hingga penyebaran jumlah individu dan kestabilan komunitas tinggi. Pertanian lahan kering, semak belukar dan pemukiman memiliki keragaman vegetasi, penyebaran dan kestabilan komunitas sedang. Semakin tinggi keragaman jenis vegetasi maka semakin banyak spesis yang dijumpai dalam tiap klaster. Hal ini dipengaruhi oleh kelimpahan spesis, kekayaan spesis dan frekuensi masing-masing spesis vegetasi pada kelima klaster. Semakin banyak jumlah jenis vegetasi maka semakin tinggi keragaman yang menunjukan hubungan antara jumlah spesis dengan jumlah individu yang menyusun satu komunitas (Heddy, 1994). Sebuah komunitas dikatakan mempunyai keragaman spesis yang tinggi apabila jumlah individu masing-masing spesis tersebut terdapat dalam jumlah yang sama atau hampir sama. Sebaliknya apabila komunitas tersebut tersusun hanya satu spesis, atau hanya beberapa spesis yang kepadatannya rendah maka komunitas tersebut dikatakan mempunyai keragaman rendah (Budhi, 2006). Beberapa faktor yang diduga sangat mempengaruhi keragaman vegetasi yakni ketinggian tempat. Semakin tinggi tempat dari permukaan laut maka spesis vegetasi semakin sedikit dan sebaliknya. Kelima klaster terletak pada ketinggian antara $100 \quad-500 \mathrm{~m}$ dpl sehingga kekayaan, kelimpahan dan frekuensi kehadiran vegetasi akan bervariasi dan mempengaruhi keragaman vegetasi dalam kawasan hutan lindung, kesuburan tanah. Jenis tanah dapat mempengaruhi kesuburan tanah dalam sebuah ekosistem dan menyebabkan perbedaan jumlah maupun jenis vegetasi yang tumbuh diatasnya serta penebangan pohon dan kebakaran hutan akibat kemarau.

Kemerataan vegetasi pada kelima klaster bervariasi dari rendah hinggi tinggi. Pada hutan primer dan sekunder indeks kemerataan vegetasi rendah. Hal ini menunjukan bahwa jenis vegetasi dalam hutan primer dan sekunder penyebarannya tidak merata, karena jenis vegetasinya bervariasi dan tidak mendominasi dalam klaster. Pada areal 
pertanian lahan kering dengan indeks kemerataan sedang menunjukan variasi jenis vegetasi dan sebagian spesis lagi mendominasi dalam klaster sebagai akibat dari kegiatan bercocok tanam. Warga menanam tanaman pertanian berumur pendek diantaranya ubi kayu, jagung, nenas dan ubi jalar, langsat, duku dan mangga.

\section{Respon Semut terhadap Kerusakan Antropogenik}

Pendekatan yang digunakan untuk mengetahui respon semut terhadap kerusakan habitat adalah dengan menggunakan pendekatan nilai keragaman spesis, frekuensi, komposisi dan kelimpahan spesis semut (Bilton dkk., 2006).

\section{Keragaman jenis semut}

Hasil pengukuran keragaman semut dengan Indeks keragaman Shanon menunjukan nilai indeks diversitas semut dalam hutan sekunder sebesar 2,92 dan tergolong kriteria sedang (Tabel 2). Nilai ini menunjukan bahwa penyebaran jumlah individu tiap spesis semut dan kestabilan komunitas semut sedang, ekosistem masih mantap dengan produktivitas yang cukup baik dalam kawasan hutan. Keragaman semut dalam hutan sekunder diduga dipengaruhi oleh kompetisi interspesifik, ketersediaan sumber makanan, kualitas habitat dan perubahan aktivitas semut. Penggunaan lahan oleh warga di sekitar hutan lindung untuk dijadikan areal pertanian, penggembalaan ternak dan pemukiman sangat mempengaruhi keragaman semut. Perubahan arsitektur tanaman, perubahan kondisi habitat, penggunaan insektisida secara intensif, dan perubahan iklim. Ketinggian tempat dapat mempengaruhi keragaman semut dalam satu habitat meskipun ketinggian hutan sekunder terletak antara 250-500 m dpl namun tidak mempengaruhi kekayaan, kelimpahan dan keragaman semut dalam kawasan. Hal ini dikarenakan pada batas ketinggian ini semut dapat hidup dengan baik dan diduga cocok untuk semut melakukan berbagai aktivitas yang menunjang kehidupannya.

Pada dataran tinggi terjadi penurunan keragaman semut karena perubahan peran dalam ekosistem yang digantikan oleh artropoda lain. Suhu dan kelembaban udara dapat mempengaruhi penyebaran dan perkembangan semut dalam kawasan hutan sekunder. Rata-rata suhu dan kelembaban udara mikro yakni $27{ }^{\circ} \mathrm{C}$ dan $85 \%$ diduga sesuai untuk perkembangan semut (Shattuck, 2000). Pendapat lain dari Cox dan Moore (2000) bahwa perbedaan suhu, kelembaban, pola makan dan aktivitas semut sangat berpengaruh terhadap keragaman spesis. Contohnya iklim dan pola makan dapat mengubah ukuran dan tampilan tubuh semut (Shattuck, 2000). Keragaman semut juga dipengaruhi oleh variasi ketersediaan makanan, kualitas habitat dan perubahan aktivitas semut (Bestelmeyer dan Wiens, 2000).

\section{Komposisi dan frekuensi jenis semut}

Komposisi dan frekuensi jenis semut dalam hutan sekunder dapat dilihat pada Tabel 2 . Komposisi jenis dan frekuensi kehadiran semut menunjukan hasil yang berbeda yakni ditemukan lima subfamily masing-masing Ponerinae, Myrmicinae, Formicinae, Dolichoderinae dan Cerapachyinae dengan 16 genus dan 23 spesis. Lima spesis semut dengan jumlah individu dan frekuensi tertinggi (Tabel 2) masing-masing Polyrhachis bellicosa (2626 dan 33,33 \%), Pheidole sp 1 (1656 dan 27,11 \%), Oecophylla smaragdina (1366 dan 24,89\%), Crematogaster sp 1 (1131 dan 23,56 \%) dan Pheidole sp 2 (1092 dan 22,01\% ).

$P$. bellicosa memiliki jumlah individu terbanyak dengan metode hand collecting dan pitfall trap karena ini spesis memiliki kemampuan penyebaran yang tinggi dan beragam. Umumnya spesis ini ditemukan pada daerah dataran rendah hingga sedang. Pada saat penelitian ditemukan pada batang dan ranting pohon pule (Alstonia scholaris), jambu (Eugenia sp), beringin (Ficus benjamina), bacang (Mangifera foetida), cempedak (Arthocarpus cempeden), gondal (Ficus septica), dan rotan merah (Calamus amphybolus).

Pheidole sp 1 dan Pheidole sp 2 banyak ditemukan pada permukaan tanah melalui metode pitfall trap dan hand collecting dengan frekuensi kehadiran masing-masing 27,11 dan 22,01 \%. Umumnya spesis ini mendominasi hutan hujan tropis di seluruh dunia (Andersen, 2000). Genus Pheidole berperan sebagai scavenger dan tergolong spesis epigaeic (Holldobler dan Wilson, 1990).

Oecophylla smaragdina memiliki kebiasaan yang sangat agresif. Spesis ini ditemukan sebanyak 1366 ekor dengan frekuensi 24,89\%. Aktivitas spesis ini sangat dipengaruhi suhu lingkungan antara $24-29{ }^{\circ} \mathrm{C}$ dengan kelembaban relatif antara 62-80 \% (Andersen dkk., 2004). Rata-rata suhu udara dalam hutan sekunder $27{ }^{\circ} \mathrm{C}$ dengan kelembaban udara $85 \%$ diduga sesuai dengan kebutuhan spesis semut ini. Spesis ini sangat melimpah pada tanaman mangga (Mangifera indica) dan kopi (Coffee robusta) melalui metode pengumpanan.

Crematogaster sp 1 berasal dari subfamily Myrmicinae sebanyak 1131 ekor. Spesis ini merupakan spesis arboreal, ditemukan cukup banyak menjelajahi batang pepohonan, ranting dan cabang pohon tusam (Pinus merkusii Jung Et de Vriese), lenggua (Pterocarpus indicus), kayu merah (Eugenia rumphii) dan asam jawa (Tamarinus 
Tabel 2. Frekuensi dan keragaman jenis semut dalam hutan sekunder.

\begin{tabular}{lccc}
\hline \multicolumn{1}{c}{ Jenis semut } & Jumlah individu & Frekuensi & Keragaman jenis \\
\hline Polyrhachis bellicosa & 2626 & 33,33 & 0,291 \\
Pheidole sp 1 & 1656 & 27,11 & 0,229 \\
Oecophylla smaragdina & 1366 & 24,89 & 0,205 \\
Crematogaster sp 1 & 1131 & 23,56 & 0,179 \\
Pheidole sp 2 & 1092 & 22,00 & 0,178 \\
Polyrhachis dives & 921 & 19,11 & 0,160 \\
Cerapachys sp 1 & 901 & 17,56 & 0,154 \\
Hypoponera sp 1 & 779 & 16,44 & 0,143 \\
Iridomyrmex anceps & 663 & 16,22 & 0,128 \\
Dolichoderus beccarii & 615 & 15,78 & 0,122 \\
Platythyrea parallela & 614 & 13,78 & 0,121 \\
Anochetus graeffei & 599 & 13,56 & 0,119 \\
Rhoptromyrmex wroughtonii & 583 & 12,89 & 0,117 \\
Polyrachis sp 3 & 550 & 11,56 & 0,112 \\
Dolichoderus thoracicus & 523 & 11,33 & 0,108 \\
Hypoponera sp 2 & 507 & 11,33 & 0,106 \\
Leptogenys diminuta & 419 & 9,56 & 0,092 \\
Hypoponera sp 3 & 394 & 5,11 & 0,088 \\
Meranoplus bicolor & 316 & 4,67 & 0,075 \\
Echinopla lineata & 303 & 3,56 & 0,073 \\
Lophomyrmex opaciceps & 268 & 3,11 & 0,066 \\
Lophomyrmex sp 1 & 238 & 2,67 & 0,060 \\
Cardiocondyla nuda & 195 & 1,56 & 0,052 \\
\hline Total & 16601 & 304,38 & 2,922 \\
\hline
\end{tabular}

indica). Subfamily ini bersifat omnivora, berperilaku seperti pemburu karena kasta pekerja cukup agresif dan akan menyerang jika diganggu. Berperan sebagai predator hemiptera, namun dapat pula sebagai pemakan madu dengan melindungi hemyptera dari predator lainnya (Nakamura dkk., 2007).

\section{Kelimpahan Jenis Semut.}

Kelimpahan jenis (species abundance) semut dalam hutan sekunder dapat dilihat pada Tabel 3 . Kelimpahan jenis semut berkaitan dengan jumlah individu dan frekuensi kehadiran semut dalam satu habitat. Semakin tinggi jumlah individu dan frekuensi kehadiran semut maka kelimpahan jenis akan semakin tinggi dan sebaliknya. Kelimpahan jenis tertinggi pada Polyrhachis bellicosa sebesar 0,158 dan terendah pada Cardiocondyla nuda sebesar 0,011. Variasi nilai kelimpahan jenis diduga dipengaruhi oleh faktor iklim, ketersediaan makanan, ketinggian tempat, kandungan bahan organik dan nilai pH tanah. Pada suhu udara yang terlalu tinggi beberapa proses fisiologis seperti reproduksi, metabolisme dan respirasi semut akan terganggu. Suhu udara yang sesuai untuk pertumbuhan semut antara $15-27^{\circ} \mathrm{C}$, dimana suhu yang lebih tinggi bersifat toleran apabila terdapat naungan yang cukup dengan kelembaban optimal (Rizali, 2007). Rata-rata suhu udara pada saat penelitian yakni $27{ }^{\circ} \mathrm{C}$ dengan kelembaban udara sebesar $85 \%$ diduga sangat cocok untuk aktivitas
Tabel 3. Kelimpahan jenis semut dalam hutan sekunder.

\begin{tabular}{|c|c|c|}
\hline Subfamily & Jenis semut & $\begin{array}{c}\text { Kelimpahan } \\
\text { jenis }\end{array}$ \\
\hline \multirow[t]{5}{*}{ Formicinae } & $\begin{array}{l}\text { Polyrhachis bellicosa } \\
\text { Oecophylla }\end{array}$ & 0,158 \\
\hline & smaragdina & 0,082 \\
\hline & Polyrhachis dives & 0,046 \\
\hline & Polyrachis sp 3 & 0,033 \\
\hline & Echinopla lineata & 0,018 \\
\hline \multirow[t]{9}{*}{ Myrmicinae } & Pheidole sp 1 & 0,099 \\
\hline & Crematogaster sp 1 & 0,065 \\
\hline & Pheidole sp 2 & 0,055 \\
\hline & Rhoptromyrmex & \\
\hline & wroughtonii & 0,035 \\
\hline & $\begin{array}{l}\text { Meranoplus bicolor } \\
\text { Lophomyrmex }\end{array}$ & 0,019 \\
\hline & opaciceps & 0,016 \\
\hline & Lophomyrmex sp 1 & 0,014 \\
\hline & Cardiocondyla nuda & 0,011 \\
\hline Cerapachyinae & Cerapachys sp 1 & 0,041 \\
\hline \multirow[t]{6}{*}{ Ponerinae } & Hypoponera sp 1 & 0,041 \\
\hline & Platythyrea parallela & 0,036 \\
\hline & Anochetus graeffei & 0,036 \\
\hline & Hypoponera sp 2 & 0,030 \\
\hline & Leptogenys diminuta & 0,025 \\
\hline & Hypoponera sp 3 & 0,023 \\
\hline \multirow[t]{3}{*}{ Dolichoderinae } & Iridomyrmex anceps & 0,039 \\
\hline & $\begin{array}{l}\text { Dolichoderus beccarii } \\
\text { Dolichoderus }\end{array}$ & 0,037 \\
\hline & thoracicus & 0,031 \\
\hline
\end{tabular}

semut. Suhu udara berbanding lurus dengan kelimpahan, distribusi dan keragaman semut. Hal ini sejalan dengan keberadaan semut sebagai 
organisme thermopholic yang sangat dipengaruhi oleh keadaan lingkungan. Semut menyukai udara yang sejuk dan lembab dan tidak terlalu panas untuk aktivitas harian dan reroduksinya (Shattuck, 2000).

Faktor ketersediaan vegetasi dalam hutan sekunder juga dapat mempengaruhi keragaman dan kelimpahan semut, karena semut memanfaatkan vegetasi sebagai sumber bahan makanan, tempat bersarang, habitat dan tempat berlindung. Faktor ketinggian tempat dapat mempengaruhi kelimpahan semut dalam hutan sekunder, karena semakin tinggi ketinggian tempat maka akan semakin menurun kelimpahan spesisnya. Ketinggian hutan sekunder antara 250-500 m dpl diduga cocok bagi penyebaran semut dalam kawasan hutan sekunder. Perbedaan umur tanaman juga dapat mempengaruhi kelimpahan spesis semut karena berhubungan dengan ketersediaan dan kualitas makanan. Pada saat penelitian ditemukan banyak sarang pada beberapa pohon yakni akasia (Acacia mangium), salawaku (Paraserianthes falcataria), ekaliptus (Eucalyptus alba) dan durian (Durio zibethinus) yang diduga sangat disukai oleh semut dimana pepohonan ini dijadikan sebagai tempat bersarang dan sumber makanan bagi semut.

Kerusakan antropogenik melalui tindakan pengalihan fungsi kawasan dan pembukaan kawasan hutan untuk dijadikan sumber kayu bakar, sumber bahan makanan, lahan pengembalaan ternak dapat mempengaruhi kekayaan, kelimpahan, keragaman dan kekayaan spesis semut dalam hutan lindung. Hal ini sependapat dengan (Garden dkk., 2007) bahwa perilaku manusia akan menurunkan keragaman jenis dan meningkatkan dominansi semut dan menimbulkan ketidakstabilan biodiversitas.

\section{Kelompok fungsional semut}

Pengelompokan semut secara fungsional didasari pada respon semut terhadap kerusakan dan gangguan yang terjadi dalam habitat tempat hidupnya (Underwood dan Fisher, 2006). Untuk melihat respon semut terhadap kerusakan antropogenik dalam hutan sekunder dapat dilihat pada Tabel 4.

Semut dalam hutan sekunder menunjukan respon yang berbeda dalam menanggapi tekanan dan gangguan yang terjadi dalam habitatnya. Spesis yang memberikan respon sama dikelompokkan dalam satu tipe fungsional yang sama dan spesis yang berbeda respon akan dikelompokan dalam tipe fungsional yang berbeda. Dalam hutan sekunder terdapat tujuh tipe kelompok fungsional (Tabel 4) yakni oppurtunist (1 spesis), generalized myrmicinae (1 spesis), specialis predator (4 spesis), tropical climate specialis (6 spesis), dominant
Tabel 4. Kedudukan semut secara fungsional dalam hutan sekunder.

\begin{tabular}{|c|c|c|}
\hline Jenis semut & Kelompok fungsional & $\begin{array}{l}\text { Kelimpahan } \\
\text { jenis }\end{array}$ \\
\hline Polyrhachis & Subordinate & 0,158 \\
\hline bellicosa & Camponitini & \\
\hline Pheidole sp 1 & $\begin{array}{l}\text { Dominant } \\
\text { Dolichoderinae }\end{array}$ & 0,099 \\
\hline $\begin{array}{l}\text { Oecophylla } \\
\text { smaragdina }\end{array}$ & $\begin{array}{l}\text { Tropical Climate } \\
\text { spesialis }\end{array}$ & 0,082 \\
\hline Pheidole sp 2 & $\begin{array}{l}\text { Dominant } \\
\text { Dolichoderinae }\end{array}$ & 0,055 \\
\hline $\begin{array}{l}\text { Polyrhachis } \\
\text { dives }\end{array}$ & $\begin{array}{l}\text { Subordinate } \\
\text { Camponitini }\end{array}$ & 0,046 \\
\hline Cerapachys sp 1 & Cryptic species & 0,041 \\
\hline Hypoponera sp 1 & Cryptic species & 0,043 \\
\hline $\begin{array}{l}\text { Iridomyrmex } \\
\text { anceps }\end{array}$ & $\begin{array}{l}\text { Dominant } \\
\text { Dolichoderinae }\end{array}$ & 0,039 \\
\hline $\begin{array}{l}\text { Dolichoderus } \\
\text { beccarii }\end{array}$ & $\begin{array}{l}\text { Dominant } \\
\text { Dolichoderinae }\end{array}$ & 0,037 \\
\hline $\begin{array}{l}\text { Platythyrea } \\
\text { parallela }\end{array}$ & Specialis predators & 0,036 \\
\hline $\begin{array}{l}\text { Anochetus } \\
\text { graeffei }\end{array}$ & Specialis predators & 0,035 \\
\hline $\begin{array}{l}\text { Rhoptromyrmex } \\
\text { wroughtonii }\end{array}$ & $\begin{array}{l}\text { Subordinate } \\
\text { Camponitini }\end{array}$ & 0,035 \\
\hline Polyrachis sp 3 & $\begin{array}{l}\text { Subordinate } \\
\text { Camponitini }\end{array}$ & 0,033 \\
\hline Hypoponera sp 2 & Cryptic species & 0,030 \\
\hline Hypoponera sp 3 & Cryptic species & 0,023 \\
\hline $\begin{array}{l}\text { Meranoplus } \\
\text { bicolor }\end{array}$ & $\begin{array}{l}\text { Tropical Climate } \\
\text { spesialis }\end{array}$ & 0,019 \\
\hline $\begin{array}{l}\text { Echinopla } \\
\text { lineata }\end{array}$ & $\begin{array}{l}\text { Subordinate } \\
\text { Camponitini }\end{array}$ & 0,018 \\
\hline $\begin{array}{l}\text { Lophomyrmex } \\
\text { opaciceps }\end{array}$ & $\begin{array}{l}\text { Tropical } \\
\text { spesialis }\end{array}$ & 0,016 \\
\hline $\begin{array}{l}\text { Lophomyrmex } s p \\
1\end{array}$ & $\begin{array}{l}\text { Tropical Climate } \\
\text { spesialis }\end{array}$ & 0,014 \\
\hline $\begin{array}{l}\text { Cardiocondyla } \\
\text { nuda }\end{array}$ & Oppurtunist & 0,011 \\
\hline
\end{tabular}

dolichoderinae (4 species), subordinate camponitini (6 spesis) dan criptic species ( 4 spesis)

Semut opportunist umumnya hidup pada areal yang terganggu sebagai akibat kehadiran manusia atau pada daerah dengan tingkat diversitas yang rendah (Giller, 2002). Habitat yang terganggu dapat mempengaruhi produktivitas semut dan tingkat keragamannya. Kelompok ini memiliki areal jelajah yang luas sehingga dapat ditemukan di berbagai tempat. Tipe opportunist biasanya hidup pada habitat yang memiliki fluktuasi suhu yang tinggi, kelembaban relatif rendah dan penutupan kanopi yang rendah khususnya areal hutan yang masih muda (Whitmore, 2000). Kelompok semut ini mengambil keuntungan dari gangguan yang terjadi dalam habitat, tidak mampu berkompetisi karena distribusinya sangat dipengaruhi oleh kompetisi dari semut lain. Distribusi habitat sangat luas, namun hanya mendominasi pada wilayah dengan 
tingkat tekanan dan gangguan yang tinggi sehingga akan membatasi produktivitas dan keragaman semut (Holldobler dan Wilson, 1990). Kelimpahan spesis opportunist berubah selama suksesi hutan sehingga terdapat hubungan yang linear antara kelimpahan spesis dengan umur hutan hujan tropis (House dkk., 2006). Kelompok fungsional dominant dolichoderinae ditemukan sangat melimpah, sifatnya sangat aktif dan agresif serta terjadi persaingan yang kuat antara koloni dan umumnya berperan sebagai forager. Jumlahnya sangat melimpah pada beragam habitat khususnya daerah tropis, dengan tingkat aktivitas mencari makan sangat tinggi. Kelompok ini merupakan taksa yang sangat dominan, bersifat kompetitif dan mendominasi lingkungan yang mengalami gangguan. Kelompok fungsional subordinate camponitini umumnya berukuran tubuh besar, banyak beraktivitas dari pagi hingga malam hari. Perilaku kelompok ini menyerupai tipe dominant dolichoderinae dengan berperan sebagai forager. Kelompok ini tidak sekompetitif semut lain dan biasanya ditemukan dalam jumlah yang sedikit pada tiap tipe habitat (Holldobler dan Wilson, 1990).

Kelompok generalized myrmicinae bersifat kosmopolitan karena dapat ditemukan di berbagai tipe habitat yang sesuai dengan kebutuhannya. Umumnya saling membantu apabila ada anggota koloni yang diserang. Bersifat mengelompok dalam pencarian makanan dan cenderung memiliki wilayah pencarian makan yang tidak jauh. Kelimpahan spesis ini berubah selama suksesi hutan sehingga terdapat hubungan yang linear antara kelimpahan spesis semut ini dengan umur hutan hujan tropis. Tipe ini mampu bersaing pada habitat yang kaya akan sumber daya. Kelompok fungsional tropical climate spesialis umumnya bersifat generalized foragers dalam hutan sekunder dengan perannya sebagai predator, seed harvester dan scevenger. Umumnya hidup pada habitat yang memiliki fluktuasi suhu yang tinggi, kelembaban relatif rendah dan penutupan kanopi yang rendah
(Stephens dan Wagner, 2006). Kelompok fungsional spesialis predator umumnya berperan sebagai predator dalam jaring makanan. Senang memangsa arthropoda lain, jumlah spesisnya rendah karena sangat tergantung pada mangsa dan umumnya memiliki interaksi yang rendah dengan semut lain. Kelompok cryptic species umumnya hidup di permukaan tanah, dalam tanah dan serasah, bersifat generalized foragers, serta mempunyai hubungan dengan semut epigeic (Stephens dan Wagner, 2006).

\section{Parameter lingkungan.}

Faktor iklim dan tanah digunakan sebagai paramater untuk melihat hubungannya dengan kehidupan semut, karena aktivitas semut ditentukan oleh faktor iklim dan tanah sebagai habitatnya (Purwanto dan Gintings, 2007). Data hasil pengukuran parameter lingkungan disajikan pada Tabel 5.

Suhu udara dalam hutan sekunder diduga sangat mendukung kehidupan semut yang hidup dalam habitat. Hal ini sependapat dengan Rizali (2007) bahwa suhu udara yang sesuai untuk aktivitas semut yakni antara $15-28{ }^{\circ} \mathrm{C}$. Nilai $\mathrm{pH}$ tanah sebesar 6,2 menunjukkan bahwa tanah hutan sekunder bersifat asam dan mampu menunjang kehidupan semut. Keberadaan dan kepadatan semut sangat tergantung pada $\mathrm{pH}$ tanah. Semut biasanya dapat hidup pada tanah dengan $\mathrm{pH}$ asam maupun $\mathrm{pH}$ basa, sehingga dominasi semut sangat dipengaruhi oleh $\mathrm{pH}$ tanah. Nilai $\mathrm{pH}$ tanah yang ideal untuk kehidupan semut berkisar dari 4,5 - 6,8

Tabel 5. Parameter lingkungan dalam hutan sekunder.

\begin{tabular}{lc}
\hline Parameter lingkungan & Nilai \\
\hline Suhu tanah & $26,3{ }^{\circ} \mathrm{C}$ \\
Suhu udara & $27,9{ }^{\circ} \mathrm{C}$ \\
pH tanah & 6,20 \\
Kandungan bahan organik ( \% ) & 5,49 \\
Kelembaban udara ( \% ) & 85,01 \\
\hline
\end{tabular}

Tabel 6. Korelasi semut dengan vegetasi dan faktor lingkungan.

\begin{tabular}{|c|c|c|c|c|c|c|c|c|c|}
\hline Parameter & & $\mathrm{pH}$ tanah & $\begin{array}{l}\text { Kandungan } \\
\text { bahan } \\
\text { organik }\end{array}$ & $\begin{array}{l}\text { Suhu } \\
\text { tanah }\end{array}$ & $\begin{array}{l}\text { Suhu } \\
\text { udara }\end{array}$ & $\begin{array}{l}\text { Kelem- } \\
\text { baban } \\
\text { udara }\end{array}$ & $\begin{array}{l}\text { Jumlah } \\
\text { individu } \\
\text { vegetasi }\end{array}$ & $\begin{array}{l}\text { Kelimpahan } \\
\text { jenis } \\
\text { vegetasi }\end{array}$ & $\begin{array}{l}\text { Keragaman } \\
\text { jenis vegetasi }\end{array}$ \\
\hline \multirow{3}{*}{$\begin{array}{l}\text { Jumlah } \\
\text { Individu } \\
\text { semut }\end{array}$} & Korelasi Pearson & 0,607 & 0,319 & 0,695 & 0,560 & 0,130 & $0,952(* *)$ & $0,940(* *)$ & $0,908(*)$ \\
\hline & Sig. (2-tailed) & 0,201 & 0,537 & 0.125 & 0,248 & 0,807 & 0.003 & 0,005 & 0,012 \\
\hline & $\mathrm{N}$ & 6 & 6 & 6 & 6 & 6 & 6 & 6 & 6 \\
\hline \multirow{3}{*}{$\begin{array}{l}\text { Kelim- } \\
\text { pahan } \\
\text { spesis } \\
\text { semut }\end{array}$} & Korelasi Pearson & 0,769 & 0,480 & $0,882(*)$ & 0,729 & 0,262 & $0,974(* *)$ & $0,908(*)$ & $0,972(* *)$ \\
\hline & Sig. (2-tailed) & 0,074 & 0,335 & 0,020 & 0,100 & 0,616 & 0,001 & 0,012 & 0,001 \\
\hline & $\mathrm{N}$ & 6 & 6 & 6 & 6 & 6 & 6 & 6 & 6 \\
\hline \multirow{3}{*}{$\begin{array}{l}\text { Frekuensi } \\
\text { kehadiran } \\
\text { semut }\end{array}$} & Korelasi Pearson & 0,562 & 0,308 & 0,710 & 0,505 & 0,195 & $0,988(* *)$ & $0,976(* *)$ & $0,976(* *)$ \\
\hline & Sig. (2-tailed) & 0,246 & 0,552 & 0,114 & 0,307 & 0,712 & 0.000 & 0,001 & 0,001 \\
\hline & $\mathrm{N}$ & 6 & 6 & 6 & 6 & 6 & 6 & 6 & 6 \\
\hline
\end{tabular}


(Suin, 1997). Kandungan bahan organik sebesar $5,49 \%$ yang tergolong kriteria sedang sangat berpengaruh terhadap kehidupan semut. Hal ini terlihat dari keragaman jumlah individu yang tinggi, jumlah spesis, kekayaan spesis, indeks keragaman dan kelimpahan semut. Bahan organik yang tinggi dapat meningkatkan populasi semut dan mampu melindungi koloni semut dari tekanan lingkungan dan kemungkinan adanya predator yang merugikan. Semut akan mengambil nutrisi dari bahan organik tanah sehingga ketersediaan bahan organik tanah yang cukup sangat mempengaruhi kelimpahan dan keragaman semut (Herwina dkk., 2013).

\section{Korelasi Semut dengan Vegetasi dan Faktor Lingkungan}

Tabel 6 memperlihatkan hubungan semut dengan vegetasi, tanah dan iklim. Vegetasi berhubungan erat dengan kehidupan semut karena vegetasi menyediakan sumber makanan, tempat bersarang dan tempat perlindungan bagi semut. Suhu tanah berkontribusi terhadap kehidupan semut karena berkaitan dengan aktivitas harian semut di dalam tanah. Suhu tanah berhubungan erat dengan kehadiran dan kepadatan semut, karena suhu tanah akan menentukan tingkat dekomposisi material organik tanah (Herwina dkk., 2013).

\section{KESIMPULAN}

Kerusakan habitat hutan lindung Sirimau disebabkan karena faktor alam (non antropogenik) dan faktor manusia (antropogenik). Faktor antropogenik sangat berkontribusi terhadap kerusakan habitat hutan lindung sekunder melalui tindakan pembukaan wilayah hutan, penebangan pohon, pembakaran hutan, perladangan berpindah dan pembangunan fisik. Kerusakan antropogenik menimbulkan fragmentasi dan degradasi habitat yang diikuti dengan ketidakseimbangan lingkungan dan komponen ekosistem.

Semut mengalami dampak negatif akibat degradasi dan fragmentasi habitat dimana kekayaan, kelimpahan, keragaman dan frekuensi semut mengalami fluktuasi dalam habitat. Semut memiliki peran yang sangat penting dalam hutan sekunder sehingga keberadaannya harus tetap dijaga sebagai bagian dari komponen pendukung ekosistem. Aktivitas manusia harus dibatasi dalam kawasan hutan sekunder untuk menjaga kelangsungan hidup komunitas semut dan komponen pendukung ekosistem lainnya.

\section{DAFTAR PUSTAKA}

Anonim, 2009. Statistik Kehutanan Indonesia. Kementerian Kehutanan Indonesia. Jakarta, Pp 56-57

Anonim, 2010. Ant parataxonomic Training Book Course, AneT University of Malaya, Kualalumpur. Pp 21-56

Anonim, 2013. Statistik Kehutanan Indonesia. Kementerian Kehutanan Indonesia. Jakarta, Pp 90-97

Agosti, D., Majer, J., Alonso, L., dan Schultz, T., 2000. Ants Standard Methods for Measuring and Monitoring Biodiversity. Smithsonian Institution Pr. Washington. Pp 11-35

Agosti, D., dan Alonso, L., 2000. Biodiversity Studies, Monitoring, and Ants : An Overview. dalam Agosti, D., Majer, J., Alonso, L., dan Schultz, T., ( ed) Ants: Standard Methods for Measuring and Monitoring Biodiversity, Smithsonian Institution Press. Washington. Pp 35-48

Andersen, A., 2000. Global Ecology of Rainforest Ants: Functional Groups in Relation to Enviromental Stress and Disturbance, dalam Agosti, D., Majer, J.,Alonso, L., dan Schultz, T (ed) Ants: Standard Methods for Measuring and Monitoring Biodiversity. Smithsonian Institution Pr. Washington. pp 55-62.

Andersen, A., Fisher, A., Hoffmann , B., Read , J., dan Richards, R., 2004. Use of Terrestrial Invertebrates for Biodiversity Monitoring in Australian Rangelands, with Particular Reference to Ants. Austral. Ecol., 29:87-89

Barbour,. Bilton, D. Laurent,M,. 1999. Number Of Species Ants. Australia Ecology . 23 : Pp 90 95.

Bestelmeyer, B., dan Wiens, J., 2000. The Effects of Land Use on The Structure of GroundForaging Ant Communities in The Argentine Chaco. Austral. Ecol., 67:137-145.

Bilton, D., Mc Abendroth, L., Bedford, A., dan Ramsay, P., 2006. How Wide to Cast the Net? Cross-Taxon. Congruence of Species Richness, Community Similarity and Indicator Taxa in Ponds. Freshwater Biol., 51:578-590.

Bolton, B., dan Alpert, G., 2011. Barry Bolton's Synopsis of the Formicidae and Catalogue of Ants of the World. Retrieved from: http://gap.entclub.org/

Budhi,. 2006. Keragaman Fauna di Permukaan Tanah di Hutan Lindung Gunung Nona Ambon. Tesis. Program Pascasarjana Fakultas Pertanian Universitas Pattimura Ambon. Pp $41-46$. 
Cox, C., dan Moore, D., 2000. Biogeography : an Ecological and Evolutionary Approach. 6th (ed). Blackwell Science Ltd. Sydney. Pp 187196.

Djayadiningrat,.1990. Ekologi Vegetasi. Gilang Perkasa Yogyakarta. Pp 28 - 30

Garden, J., McAlpine, B.,Possingham, C.,dan Jones, N.,2007. Habitat Structure is More Important Than Vegetation Composition for Local Level Management Terrestrial Reptile and Small Mammal Species Living in Urban Remnants: A Case Study from Brisbane, Australia. Austral Ecol (32):669-685.

Giller, G., 2002. Biodiversity and Ecosystem Function: Do Species Matter ? Biology and Environment. (3):129-139

House, A., Burwell, C., dan Brown, S., 2006. Ant assemblage in Brigalow regrowth vegetation. Journal Ecol Manage Restor (7):136-140.

Hashimoto, Y.,Yamane, S.,dan Mohamed, M., 2001. How to Design an Inventory Method for Ground Level Ants in Tropical Forests. Nature and Human Activitie. Pp 167-170

Herwina, H., Nasir, N., Jumjunidang, M.,dan Yaherwandi, M., 2013. The Composition of Ant Species on Banana Plants With Banana Bunchy Top Virus (BBTV) Symptoms in West Sumatera, Indonesia. Jurnal Asian Myrmicology, 5:151-155

Holldobler, B., dan Wilson, E., 1990. The Ants. Cambridge Massachusetts: Harvard Univ Pr. Pp 17-44.

Indriyanto, . 2006. Ekologi Mahkluk Hidup. Sumber Rejeki, Yogyakarta. Pp 34 -35.

Irwanto,. 2005. Ekologi Vegetasi Pulau Marsegu. Tesis. Program Pascasarjana Fakultas kehutanan . Yogyakarta. Pp 89 -95.

Majer, J., dan Nichols, O., 1998. Long Term Recolonization Patterns of Ants in Western Australian Rehabilitated Bauxite Mines with Reference to Their Use as Indicators of Restoration Success. Journal Appl Ecol (35): 161-182.

Nakamura, A., Catterall, C., House, A., Kitching, R., dan Burwell, C., 2007. The Use of Ants and Other Soil and Litter Arthropods as Bioindicators of The Impacts of Rainforest Clearing and Subsequent Land Use. Journal Insect Conserv. 11:177-186.

Pecarevic, M., 2010. Biodiversity on Broadway Enigmatic Diversity of the Societies of Ants
(Formicidae) on The Streets of New York City. Journal Appl Ecol 5(10):121-125

Purwanto, I., dan Gintings, A., 2007. Penelitian Sifat-sifat Fisik dan Kimia Tanah di Bawah Tegakan Hutan Alam Duabanga moluccana di Nusa Tenggara Barat. Buletin Penelitian Hutan, 561:50-60

Purwowidodo,.1996. Pengaruh Perubahan Suhu Udara Terhadap Pertumbuhan Vegetasi. (Tesis). Program Pascasarjana Fakultas Kehutanan IPB Bogor. Bogor. Pp 95 - 99

Rizali, A., 2007. Keragaman Semut di Kepulauan Seribu, Indonesia. Tesis. Program Pascasarjana, Institut Pertanian Bogor. Bogor. Pp 17-34.

Sahusilawane,. 2010. Keragaman Vegetasi Dalam Hutan Lindung Sirimau Ambon. Tesis. Program Pascasarjana Fakultas Pertanian Universitas Pattimura Ambon. Pp 21 -26.

Soekotjo, 1976. Silvikultur Intensif. Gajah Mada Press Jogyakarta. Pp 67 - 69.

Stephens, S., dan Wagner, M., 2006. Using Ground Foraging Ant (Hymenoptera: Formicidae) Functional Groups as Bioindicators of Forest Health in Northern Arizona Ponderosa Pine Forests. Environ Entomol (35) pp 937- 949

Shahabudin., 2011. Effect of Land Use Change on Ecosystem Function of Dung Beetles: Experimental Evidence From Wallacea Region in Sulawesi, Indonesia. Jurnal Biodiversitas, 3:177-181

Shattuck, S., 2000. Australian Ants: Their Biology and Identification. Collingwood: CSIRO Sydney. Pp 197-199.

Suin, M., 1997. Ekologi Hewan Tanah, Bumi Aksara, Jakarta. Pp 17-19.

Suputa dan Hasimoto, 2010. Semut di Indonesia. UGM Press, Yogyakarta. Pp 16-67

Talaohu, 2012. Kerusakan Hutan Lindung Sirimau dan Pengaruhunya Terhadap Fungsi Lindung Skripsi. Program Studi Kehutanan Universitas Pattimura, Ambon. pp 27 - 34

Underwood, E., dan Fisher, B., 2006. The Role of Ants in Conservation Monitoring : if, When, and How. Biol. Conserv. 132:166-182

Whitmore,T.,2000. The Case of Tropical Rain Forests. The Sustainable Development of Forests: Aspirations and The Reality. Naturzale, 15:13-15. 